\title{
PERANCANGAN APLIKASI UNTUK PERALATAN PEMANTAU SUHU MENGGUNAKAN RADIO FREQUENCY (RF)
}

\author{
Wahid Kurniawan, Denny Dermawan, Yuliani Indrianingsih \\ Teknik Informatika STTA Yogyakarta \\ Informatika@stta.ac.id
}

\begin{abstract}
Temperature is a part of the natural condition that related to human activities. Many human activities are affected by temperature fluctuation factors. For example, in this case is a temperature monitoring at these broiler farms and database monitoring center computer. Room temperatures for places are two examples of the human activities that the temperature factor is concerned. Until now, time temperature monitoring activity is done manually, thus it is need a monitoring tool that can be viewed from the computer interface.

To save time and cost, application for temperature monitoring equipment is made so that the results can be seen from a distance. The applications are user friendly, so users can easily flnd out the temperature value.

Application for temperature monitoring equipment is useful to support the activities of monitoring the temperature. From the experimental results, the application for temperature monitoring equipment that uses radio frequency results can be viewed from a computer interface, so as to streamline the performance of temperature monitoring.
\end{abstract}

Keyword: Temperature, Monitoring, Application

Intisari

Suhu merupakan bagian dari kondisi alam yang sangat berhubungan dengan aktivitas manusia. Banyak aktivitas dari manusia yang dipengaruhi oleh faktor naik turunnya suhu. Sebagai contoh dalam kasus ini adalah pemantauan suhu di peternakan ayam pedaging dan pemantauan suhu ruang database center komputer karena dua tempat tersebut adalah contoh bagian dari aktivitas manusia yang faktor suhu sangat diperhatikan. Selama ini aktivitas pemantauan suhu masih banyak yang dilakukan secara manual, untuk itu diperlukan suatu alat pemantau yang bisa di lihat dalam interface komputer.

Untuk menghemat waktu dan biaya, dibuat aplikasi untuk peralatan pemantau suhu yang hasilnya dapat dilihat dari jarak jauh. Aplikasi ini bersifat user friendly agar user lebih mudah mengetahui besaran suhu tersebut.

Aplikasi untuk peralatan pemantau suhu ini berguna untuk mendukung aktivitas pemantauan suhu. Dari hasil percobaan, aplikasi untuk peralatan pemantau suhu yang menggunakan radio frequency hasilnya dapat dilihat dari interface komputer, sehingga dapat mengefektifkan kinerja pemantauan suhu.

Kata kunci: Suhu, Pemantau, Aplikasi 


\section{Latar Belakang}

Saat ini, perpindahan informasi secara cepat dan tepat menjadi kebutuhan manusia yang cukup penting. Hampir setiap orang, organisasi atau perusahaan membutuhkan informasi untuk mendukung kegiatanya. Salah satu perpindahan informasi yang cukup penting adalah informasi suhu pada tempat-tempat yang dikehendaki. Suhu merupakan bagian dari kondisi alam yang sangat berhubungan dengan aktivitas manusia. Banyak aktivitas dari manusia yang dipengaruhi oleh faktor naik turunnya suhu. Mengetahui dan mengamati keadaan suhu pada suatu tempat yang diperlukan, merupakan salah satu hal yang sangat penting sebagai awal dari tindakan yang akan dilakukan selanjutnya. Sebagai contoh kasus tersebut adalah penerapan teknologi untuk pemantauan kondisi suhu pada peternakan ayam pedaging dan ruang database center komputer.

Dalam pemantauan suhu seperti contoh kasus kondisi suhu pada peternakan ayam pedaging dan ruang database center komputer dalam prakteknya masih dilakukan dengan manual. Sehingga akan banyak menggunakan tenaga dan biaya yang lebih. Serta apabila akan mengabil data suhu untuk disimpan dan dianalisa harus dilakukan pencantatan manual, belum adanya database sebagai tempat untuk menyimpan data nilai suhu tersebut. Hal itu tentu tidak efektif. Maka perlu dibuat aplikasi untuk peralatan pemantau suhu.

\section{Landasan Teori}

\section{Telemetri}

Telemetri berasal dari kata "Tele" yang berarti jauh dan "Metri" yang berarti pengukuran, dengan demikian telemetri dapat diartikan sebagai proses yang digunakan untuk mengukur atau mencatat suatu besaran fisik pada suatu lokasi yang letaknya jauh dari pusat pengolahan hasil pengukuran (Sulistiyanti dkk, 2008)

\section{Visual Basic}

Visual Basic merupakan salah satu aplikasi pengembang software yang dapat dijalankan di dalam sistem operasi Microsoft Windows. Definisi Visual Basic berasal dari kata "Visual" yang dalam hal ini merupakan bahasa pemrograman yang menyerahkan berbagai macam desain dengan modul Graphical User Interface (GUI). Programer hanya harus mengetikkan sedikit kode program. Kata "Basic" menunjukkan bahasa pemrograman BASIC (Beginners All-Purpose Symbolic Instruction Code). Visual Basic menyediakan berbagai komponen yang berguna untuk mendukung dalam pembuatan aplikasi. Hal ini dipakai untuk mempermudah dalam pengembangan aplikasi tersebut.

\section{Perancangan Sistem}

Pada gambar 1 diperlihatkan blok diagram sistem interface dalam komputer menerima data suhu. Gambar tersebut dapat menjelaskan bagaimana aplikasi memperoleh data nilai suhu untuk ditampilkan dalam interface komputer. Aplikasi pemantau suhu mendapatkan data dari peralatan pemantau suhu untuk ditampilkan dalam interface komputer. 


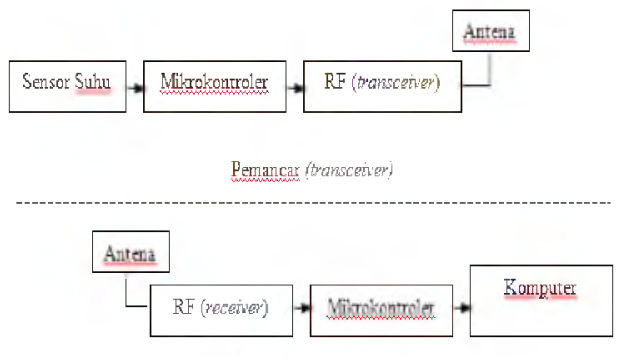

Penerima frecentiver)

Gambar 1 Blok diagram sistem

\section{Flowchart aplikasi pemantau suhu}

Diagram alir (Flowchart) adalah gambaran alur program yang terdiri dari simbol algoritma dalam suatu program, yang menyatakan arah dari alur program tersebut. Diagram alir berfungsi untuk membantu memecahkan masalah dalam pemrograman. Pada aplikasi pemantau suhu yang dibuat ini terdapat arah-arah dalam menjalankan aplikasi ini. Flowchart aplikasi diperlihatkan pada gambar 2.

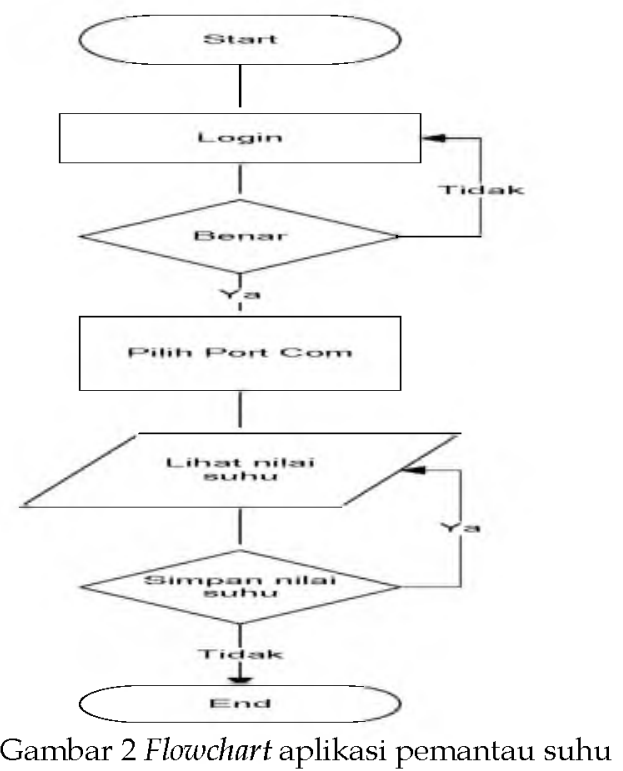

\section{Ujicoba dan Analisa}

Ujicoba aplikasi untuk peralatan pemantau suhu ini dengan mengujicoba aplikasi dan peralatan pada tempat-tempat yang ada dalam latar belakang. Untuk masuk dalam aplikasi, user diharuskan untuk mengetikkan kata kunci yang telah di konfigurasi sebelumnya. Form Login seperti pada gambar 4.

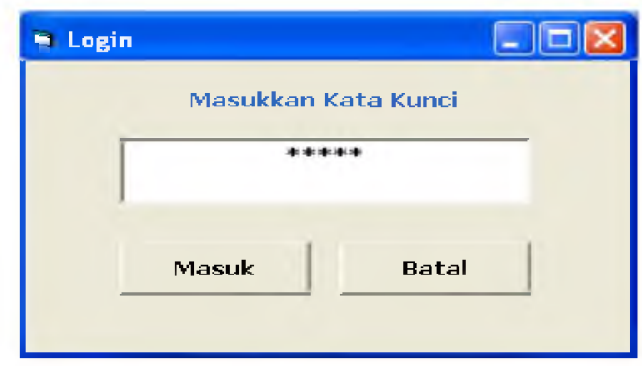

Gambar 3. Tampilan Login 
Apabila user telah benar dalam memasukkan kata kunci maka user masuk dalam form Utama, form ini berisi tombol-tombol untuk masuk ke form lain yang diinginkan. Tampilan Utama dapat dilihat pada gambar 5 .

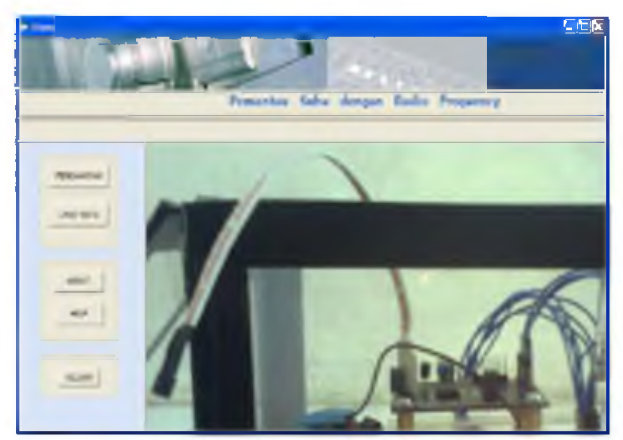

Gambar 4.Tampilan Form Menu Utama

Apabila user akan mengamati suhu yang ada maka user dapat masuk dalam Form Pengamatan, tampilan Form Pengamatan dapat di lihat pada gambar 6.

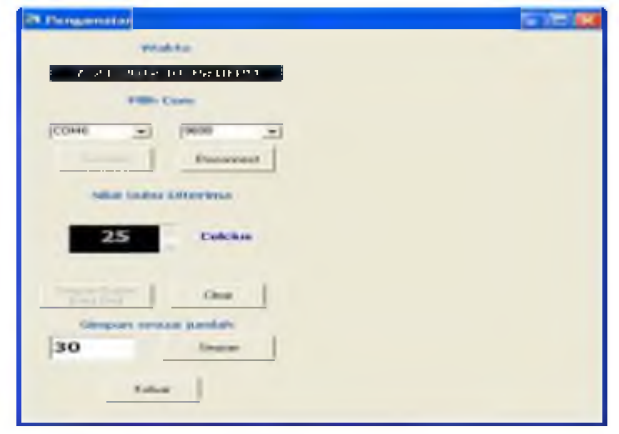

Gambar 5. Form Pengamatan

Dalam Form Pengamatan ini nilai suhu ditampilkan dalam satuan derajat celcius. Terdapat pilihan untuk menyimpan data nilai suhu dengan sekali simpan atau dengan mengetikkan dalam jumlah waktu tertentu. Misalnya user ingin menyimpan dalam kurun waktu 30 detik, maka pada textbox ketikkan dengan jumlah 30. Nilai data suhu yang dikehendaki untuk disimpan diperlihatkan dalam Form Lihat Data. Dalam form lihat data, nilai suhu diperlihatkan dalam bentuk tabel dan grafik. Dalam tabel terdiri dari 3 kolom, yaitu no, waktu dan suhu. Apabila user ingin melihat data nilai suhu dalam bentuk grafik, user dapat melihat dengan mengklik tombol lihat grafik. Form Lihat Data diperlihatkan pada gambar 7. Serta nilai data suhu yang dikehendaki tersimpan dalam database, seperti pada gambar 8 .

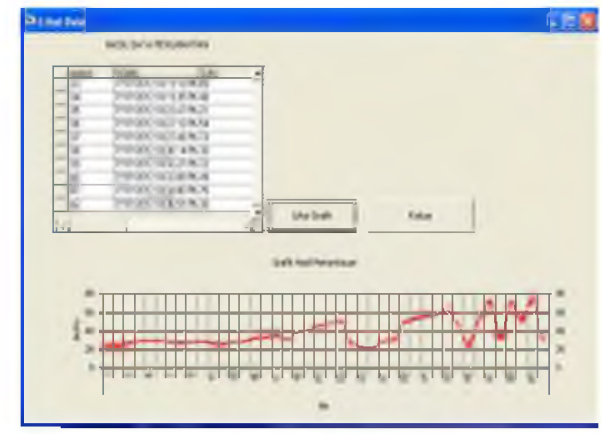

Gambar 6. Form Lihat Data 


\begin{tabular}{|c|c|c|c|c|}
\hline$x_{0}$ & Rscosolun & 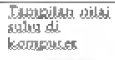 & 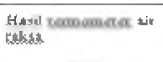 & Setersurar \\
\hline & pertoban I & $2 \mathrm{C}$ & 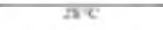 & \multirow{6}{*}{ 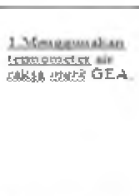 } \\
\hline 2 & Pescesbux 2 & $3 s=c$ & $2 s: C$ & \\
\hline 3 & 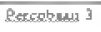 & $31=c$ & 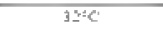 & \\
\hline 1 & 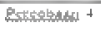 & 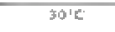 & 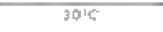 & \\
\hline 5 & Rereobsus 5 & $30=0$ & $36: c^{\prime}$ & \\
\hline 6 & Rescolonan 6 & $\because 6-c^{\prime}$ & $36=6$ & \\
\hline & 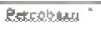 & $28 \mathrm{E}$ & $y=-15$ & \multirow{4}{*}{ 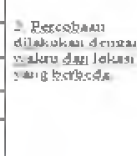 } \\
\hline$\$$ & Extsobadul 5 & 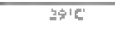 & शक्षा & \\
\hline 9 & Percobsan 9 & Iיצ' & $2 \mathrm{~s}=\mathrm{C}$ & \\
\hline 10 & Reticabsen & $y=\mathrm{C}$ & $25: c$ & \\
\hline
\end{tabular}

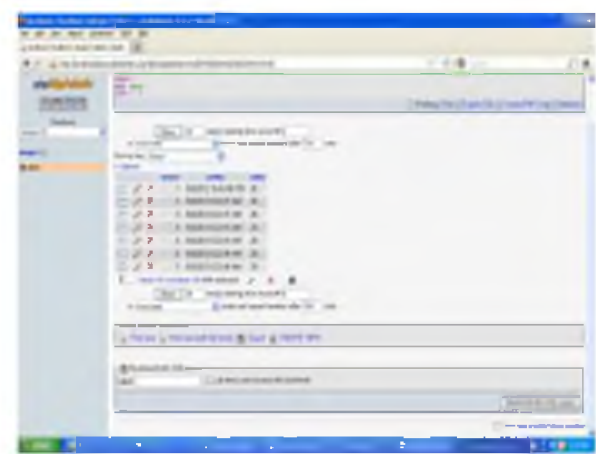

Gambar 7. Database suhu

Ujicoba meliputi ujicoba aplikasi untuk beberapa sistem operasi, perbandingan hasil sensor suhu dan termometer air raksa, menghitung waktu delay dengan jarak perangkat transceiver dan receiver yang berbeda-beda, dan reaksi sensor terhadap berbagai pemicu perubahan suhu. Ujicoba dilakukan pada beberapa sistem operasi. Sistem operasi meliputi sistem operasi Windows dan Linux. Tabel ujicoba dalam beberapa sistem operasi pada tabel 1.

\begin{tabular}{|c|c|c|}
\hline so & Sistem Operasi & Keterarigar1 \\
\hline 1 & 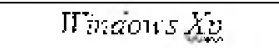 & Bisa \\
\hline 2 & TVincons T'ista & Bisa \\
\hline 3 & 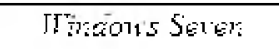 & Bisa \\
\hline 4 & 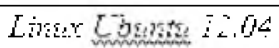 & Tidat bisa \\
\hline
\end{tabular}

Dalam ujicoba aplikasi pada beberapa sistem operasi, aplikasi dapat berjalan pada sistem operasi windows. Ujicoba juga dilakukan dengan membandingkan nilai suhu yang terdeteksi dalam aplikasi dengan sensor air raksa. Hasil ujicoba perbandingan sensor dengan termometer air raksa diperlihatkan pada tabel 2. 
Tabel 2. Hasil ujicoba perbandingan sensor dengan termometer air raksa

\begin{tabular}{|c|c|c|c|c|}
\hline so & \begin{tabular}{|l|l|} 
Rescobaur \\
\end{tabular} & 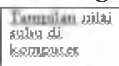 & 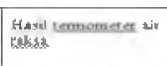 & gentraves \\
\hline & Betecabsing & 21 & 30 & \multirow{6}{*}{ 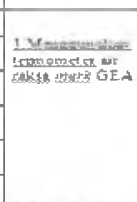 } \\
\hline$=$ & 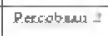 & $s s=\mathrm{C}$ & $3 \mathrm{~s}: \mathrm{C}$ & \\
\hline 3 & Pseccabman 3 & $31=C$ & $3=c$ & \\
\hline 4 & 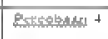 & 5 Sa'c & 3015 & \\
\hline$s$ & Retedelabal S & $30^{\circ} \mathrm{C}$ & 30.6 & \\
\hline 6 & 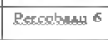 & $=6 \mathrm{C}$ & $26 \mathrm{CC}$ & \\
\hline & Petres bus " & 28 & $z^{*}$ & \multirow{4}{*}{ 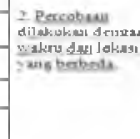 } \\
\hline$\$$ & 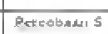 & इझाद & इुका & \\
\hline 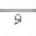 & 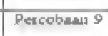 & उF्C & $38 \mathrm{C}$ & \\
\hline 10 & \begin{tabular}{|l|l|} 
Pecabban \\
I0
\end{tabular} & $2 s=\mathrm{CC}$ & $25: C$ & \\
\hline
\end{tabular}

Dalam 10 ujicoba aplikasi dengan termometer didapatkan hasil akurasi $0.47^{\circ} \mathrm{C}$ antara hasil nilai suhu pada aplikasi dengan termometer air raksa. Hasil ujicoba pembacaan sensor sampai dapat ditampilkan dalam komputer diperlihatkan pada tabel 3 dan tabel 4 .

Tabel 3. Hasil ujicoba (I) reaksi pembacaan sensor sampai dapat ditampilkan dalam komputer.

\begin{tabular}{|c|c|c|c|}
\hline$\therefore$ & $\frac{\text { Parcabaan }}{\text { in1) }}$ & 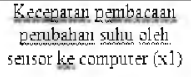 & Bsterasan \\
\hline 1 & Percobaan 1 & 14 Detilis & \multirow{10}{*}{ 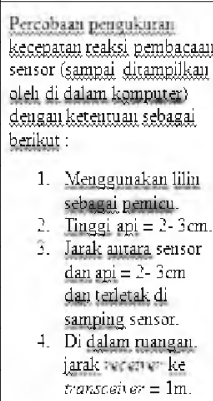 } \\
\hline 2 & Percobagil ? & $1+$ Detik & \\
\hline 3 & Percobaal 3 & 12 Detik & \\
\hline$t$ & Percobaan 4 & 15 Detik & \\
\hline 5 & Percobaan 5 & $1+$ Detik: & \\
\hline 6 & Percobagar 60 & 16 Detik & \\
\hline & Parcobagn 7 & 13 Detilik & \\
\hline 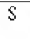 & Parcobadil $\$$ & 16 Detil: & \\
\hline 9 & Percobasing 9 & 13 Detik & \\
\hline 10 & Percobaal 10 & 15 Detik & \\
\hline
\end{tabular}

Tabel 4. Hasil ujicoba (II) reaksi pembacaan sensor sampai dapat ditampilkan dalam komputer

\begin{tabular}{|c|c|c|c|}
\hline$\therefore$ & 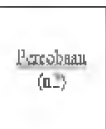 & 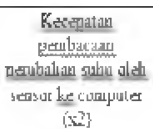 & 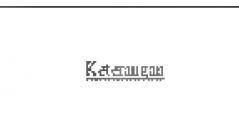 \\
\hline I & 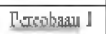 & 2 Dotul: & \multirow{10}{*}{ 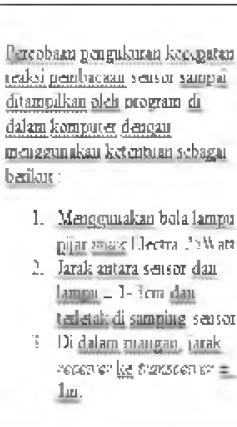 } \\
\hline 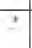 & Pencribanall: & din+ik & \\
\hline 3 & Percobasu $?$ & 3 Driik: & \\
\hline 4 & Percobatall 1 & 3 Daili: & \\
\hline 5 & 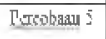 & ?Dotalis & \\
\hline 6 & l'crobsaun 6 & 2D+ti: & \\
\hline & Pencribaal & Wetik & \\
\hline$s$ & Percobaball $S$ & 2 Dexilk & \\
\hline 9 & Percobaan ? & 3 Detili: & \\
\hline 10 & Eucshagu 10 & IDotal: & \\
\hline
\end{tabular}

Pada ujicoba reaksi pembacaan sensor sampai dapat ditampilkan dalam aplikasi komputer didapatkan hasil bahwa perbedaan pemicu perubahan suhu berpengaruh terhadap waktu delay aplikasi menampilkan perubahan suhu tersebut. Ujicoba juga dilakukan dengan menghitung waktu delay dengan jarak perangkat transceiver dan receiver yang berbeda-beda. Ujicoba dengan jarak perangkat yang berbeda-beda di dalam dan di luar ruangan seperti pada tabel 5 dan tabel 6 . 
Tabel 5. Hasil ujicoba waktu delay berdasar jarak receiver dengan transceiver di ruang terbuka

\begin{tabular}{|c|c|c|c|c|c|}
\hline \multirow{2}{*}{$S_{0}$} & \multirow{2}{*}{ taus } & \multicolumn{3}{|c|}{ 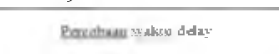 } & \multirow[t]{2}{*}{ 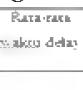 } \\
\hline & & 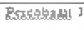 & Raratestan : & 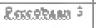 & \\
\hline 1 & $30 \mathrm{mp}$ & 1 Daik & 1 Douk & 1 Dejk & IDrakk: \\
\hline$=$ & $36 \mathrm{~m}$ & $10 \mathrm{dij}$ & $=0$ Ddik & 1 Dexilk & 15 Dotuk \\
\hline 5 & 50 㱠 & Denivg & 1 Denk & I Drejk & 13 Donk \\
\hline$\pi$ & $\sqrt{10 \mathrm{~m} m}$ & 10 ostikg & 1 Dodse & 1 Dexik & 1 Dexilk \\
\hline 5 & $\sin ^{\prime}$ & $=0$ ostik & 1 Doik & $=2 \mathrm{pos} x$ & 16 Bosulk \\
\hline 5 & 6010 & Detelk & 1 Dask & 5 Derik & 26 Donk \\
\hline & ${ }^{\circ}$ of & 3 Driak & Dank & Darik & + Derik \\
\hline 8 & Sin & SD-sith & Dossak & 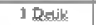 & 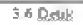 \\
\hline 5 & Sold & 5 Deik & Dentk & 4 Darik & 36 Donk \\
\hline 10 & 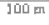 & sDrik & $5 \mathrm{~S}$ S & $8 \mathrm{DEfek}$ & Derel] \\
\hline
\end{tabular}

Dalam ujicoba waktu delay alat dan aplikasi pemantau suhu didapatkan hasil bahwa jarak berpengaruh terhadap waktu delay pengiriman data sampai dapat ditampilkan dalam aplikasi komputer.

Tabel 6. Hasil ujicoba waktu delay berdasar jarak receiver dengan transceiver di ruang terbuka

\begin{tabular}{|c|c|c|c|c|c|}
\hline \multirow{2}{*}{ sin } & \multirow{2}{*}{ Irat: } & \multicolumn{3}{|c|}{ 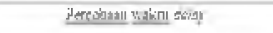 } & \multirow{2}{*}{ 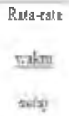 } \\
\hline & & Pacabuw 1 & percochan = & Pacibum : & \\
\hline 1 & $10 \mathrm{~m}$ & 13 jeik & 1 Drik & 1Dest: & i.j. Desub \\
\hline 2 & 50 & 1 Drik & Prili & Drit: & 15 Deruh \\
\hline j & $\mathrm{i00 \textrm {m }}$ & 2 Denits & 1 peih & 1 Dowik & 1.5 Detil \\
\hline$t$ & $10 \mathrm{~m}$ & (2) Deik & 12) & ! Dong & 13 Denit \\
\hline 5 & 湢口 & $2 \overline{D e d k}$ & I Dewih & I Deilis & 2.6 Deads \\
\hline 6 & $80 \mathrm{~m}$ & 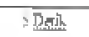 & 7pein & Deik & 5.60 . \\
\hline & $7 \mathrm{~m}$ & $5 \overline{D e d k}$ & 3 Dstuk & + Desis & + Diactik \\
\hline s & $59 \mathrm{~m}$ & $=$ Reth & Dexly & 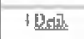 & $5 \mathrm{Set}$ \\
\hline 9 & $50 \mathrm{O}$ & 12 Dasilo & Tinesth & 5 Dall. & \begin{tabular}{|l|}
6 Dent: \\
\end{tabular} \\
\hline to & $100 \mathrm{~m}$ & Ju Dxtuk & SDstuk & \$Dril. & $562 \pi .1$ \\
\hline
\end{tabular}

Dalam ujicoba waktu delay berdasar jarak receiver dengan transceiver di ruang terbuka dan tertutup sampai dapat ditampilkan dalam aplikasi komputer. Dalam kedua ujicoba tersebut didapatkan hasil bahwa penghalang atau ruangan berpengaruh terhadap waktu delay alat dan aplikasi pemantau suhu.

\section{Kesimpulan}

1. Hardware dan software pemantau suhu dapat beroperasi dengan menggunakan media transmisi radio frequency.

2. Nilai suhu yang terbaca oleh sensor ditampilkan dalam sebuah interface komputer dalam satuan derajat celcius.

3. Perbedaan jarak antara perangkat receiver dengan transceiver berpengaruh terhadap waktu delay pengiriman data nilai suhu.

4. Aplikasi pemantau suhu dapat beroperasi pada sistem operasi windows. 


\section{Referensi}

[1] Heryanto, Ary, M, ST, dan Adi P, Wisnu, Ir., Pemrograman Bahasa C untuk Mikrokontroler ATMEGA8535, Andi Offset, Yogyakarta, 2008.

[2] Prasetio, Retno dan Edi Widodo, Catur, Teori dan Praktek Interfacing Port Paralel dan Port Serial Komputer dengan Visual Basic 6.0, Andi Offset, Yogyakarta, 2004.

[3] Sulistiyanti S, Ratna dkk, Rancang Bangun Model Sistem Pemantauan Tinggi Muka Air Sungai Menggunakan Telemetri Radio, Jurnal Unila, Lampung, 2008.

[4] Wardhana, Lingga, Belajar Sendiri Mikrokontroler AVR Seri ATMega8535 Simulasi, Hardware, dan Aplikasi, Andi Offset, Yogyakarta, 2006. 